\title{
Inspiratory flow rates at different levels of resistance in elderly COPD patients
}

\author{
W. Janssens*, P. VandenBrande**\#, E. Hardeman\#, E. De Langhe\#, T. Philps", \\ T. Troosters* and M. Decramer*
}

ABSTRACT: Dry powder inhalers (DPIs) are increasingly replacing metered dose inhalers in elderly chronic obstructive pulmonary disease (COPD) patients. However, most DPIs are dependent on inspiratory flow, which is compromised by the ageing process itself.

Using the in-check dial method, the present study compared peak inspiratory flow (PIF) rates in 26 elderly COPD patients and 14 matched control subjects, at a pre-set resistance level of the Aeroliser $_{\mathbb{}}$, Diskus ${ }_{\circledR}$ and Turbuhaler ${ }_{\circledR}$ inhalers.

It was found that the PIF measured by the in-check method positively correlated with the PIF derived from spirometry, forced vital capacity and maximal inspiratory pressure, while a negative, but significant, correlation was observed with age. PIF derived from spirometry and age were independent variables which determined PIF across the device, whereas the presence or absence of COPD was not related. When comparing elderly COPD patients with matched elderly controls no difference could be found in PIF at the different resistances. However, an important number of patients did not reach the recommended flow rate, especially when using the Turbuhaler ${ }_{\circledR}(30 \%)$.

In conclusion, the present study demonstrates that, in elderly patients, the ability to generate sufficient inspiratory flow across a dry powder inhaler is compromised, irrespective of the presence of chronic obstructive pulmonary disease.

KEYWORDS: Chronic obstructive pulmonary disease, dry powder inhaler, elderly, in-check dial, peak inspiratory flow

nhaled medication plays an important role in the treatment of chronic obstructive pulmonary disease (COPD), with dry powder inhalers (DPIs) increasingly replacing metered dose inhalers (MDIs). DPIs are interesting as they do not require the need for coordinate actuation of the MDI device with inhalation or the use of a large spacer device [1-3]. Several DPIs are available for the administration of inhaled corticosteroids, as well as bronchodilators, with each of them corresponding to a different type of inhaler (e.g. Diskus ${ }^{\circledR}$, Turbuhaler ${ }^{\circledR}$, Aeroliser ${ }^{\circledR}$, etc.). During the inspiratory effort the patient generates a pressure drop with a consequent airflow across the DPI. This inspiratory flow has to be high enough to disaggregate and adequately disperse the drug powder into an aerosol cloud of drug particles and to guarantee an optimal deposition of the medication in the lung [3-5]. Such peak inspiratory flows (PIFs) are not only dependent on a patient's inhalation effort but also on the internal resistance of the device [6-8].

It has been shown that optimal deposition of medication with DPIs is not achieved in some patients with low inspiratory flow rates, such as children [9, 10], or patients with asthma or COPD, especially during acute exacerbations [11-13]. In such conditions the use of a DPI with low internal resistance has been suggested, ensuring an optimal deposition despite the lower flow rate $[12,14]$. In addition, many clinicians are nowadays confronted with an important number of COPD patients who are aged $>70$ yrs. In this subpopulation, DPIs are often preferred to MDIs as the coordination between device and inhalation becomes increasingly difficult with age [1, $15,16]$. However, elderly subjects are known to have reduced respiratory muscle strength and decreased PIF due to the ageing process itself, which may jeopardise the adequate use of DPI independently of COPD [17].

One recent publication reports on decreased inspiratory flow rates at high levels of resistance in elderly COPD patients [18]. In view of this perspective, the present authors performed a study in which PIF was measured at different levels of resistance in elderly COPD patients and then compared with matched control subjects. It was also evaluated whether elderly COPD

\section{AFFILIATIONS}

${ }^{*}$ Respiratory Division, University Hospital Katholieke Universiteit Leuven, Leuven, and

${ }^{\text {\#}}$ Respiratory Division, Hospital SintMaarten, Duffel, Belgium

CORRESPONDENCE

W. Janssens

Respiratory Division

University Hospital Gasthuisberg

Herestraat 49

3000 Leuven

Belgium

Fax: 3216346803

E-mail:wim.janssens@

uz.kuleuven.ac.be

Received:

March 012007

Accepted after revision:

September 112007

STATEMENT OF INTEREST

None declared.
European Respiratory Journal Print ISSN 0903-1936

Online ISSN 1399-3003 
patients could generate the required PIF to overcome the internal resistance of currently available DPIs.

\section{MATERIALS AND METHODS}

\section{Study population}

The study comprised of 40 male subjects. The youngest subject was 70 yrs of age and the oldest 87 yrs of age. The 26 elderly patients with COPD were recruited from the outpatient clinic of pulmonary medicine of the Algemeen Ziekenhuis Sint Maarten (Duffel, Belgium). A diagnosis of COPD was based on a smoking history of $\geqslant 10$ pack-yrs and the Global Initiative of Chronic Lung Disease (GOLD) definition of forced expiratory volume in one second (FEV1)/forced vital capacity (FVC) $<70 \%$ predicted. The elderly control group consisted of 14 subjects without COPD, who were community dwelling and were recruited from the records of local general practitioners. These subjects completed a questionnaire and underwent a clinical examination that proved they were in good general health, were not taking pulmonary medication and had no pulmonary complaint or disease. Ethics committee (A.Z. StMaarten) approval was obtained and all participants gave informed consent.

\section{Pulmonary function measurements}

Pulmonary function variables were measured according to the European Respiratory Society guidelines for pulmonary function testing and the results were expressed as a percentage of the predicted normal values of QUANJER et al. [19]. Maximal inspiratory pressure (MIP) and maximal expiratory pressure (MEP) were measured according to a modification of the method of BLACK and HYATT [20]. MIP was measured from residual volume and MEP was measured as close as possible to total lung capacity. The highest pressure sustained for $1 \mathrm{~s}$ against a closed mouthpiece was defined as the maximum. COPD patients were asked to withhold long-acting $\beta_{2}$-agonist use for $12 \mathrm{~h}$ prior to the lung function tests. as the corresponding devices were the subject of the present study. All measurements were performed between 09:00 and 11:00 h. All manoeuvres were executed and encouraged by trained technicians under the supervision of medical staff.

\section{In-check inhaler assessment}

PIF related to different resistances was measured using the InCheck Inhaler Assessment Kit (Clement Clarke International Ltd, Harlow, UK) $[6,14,21]$. This device was used in order to compare PIF rates over three different DPIs commonly used in Belgium for the administration of long-acting $\beta_{2}$-agonists. PIF device was defined as the maximal inspiratory flow (MIF) over the device without additional resistance and compared with the MIF over the device at a given resistance of $0.1 \mathrm{cmH}_{2} \mathrm{O} \cdot \mathrm{L}^{-1} \cdot \mathrm{min}^{-1} \quad$ (Turbuhaler $\left.{ }^{\circledR}\right), \quad 0.086 \mathrm{cmH}_{2} \mathrm{O} \cdot \mathrm{L}^{-1} \cdot \mathrm{min}^{-1}$ (Diskus ${ }^{\circledR}$ ) and $0.055 \mathrm{cmH}_{2} \mathrm{O} \cdot \mathrm{L}^{-1} \cdot \mathrm{min}^{-1}$ (Aeroliser ${ }^{\circledR}$ ). The highest value of the three attempts was recorded. PIFs $>60 \mathrm{~L} \cdot \mathrm{min}^{-1}$ are generally believed to be the optimal flows for most of the devices, while PIFs $<30 \mathrm{~L} \cdot \mathrm{min}^{-1}$ are accepted to be insufficient for generating any effect $[6,22-30]$. As there is still discussion about the effectiveness of PIFs ranging 30-60 L· $\min ^{-1}[14,31$, 32], an arbitrary cut-off at a PIF of $45 \mathrm{~L} \cdot \mathrm{min}^{-1}$ was made in order to distinguish therapeutic flows from subtherapeutic levels.

\section{Statistical analyses}

Data are expressed as mean \pm SD. Subjects' characteristics and lung function tests were compared using an unpaired t-test. Correlations between different variables were expressed by Pearson correlation coefficients. A stepwise multiple regression was performed to investigate independent predictors of the PIF through the device at different resistances. Potentially important variables were FVC, FEV1, FVC \% pred, FEV1\% pred, PIF, age, inspiratory muscle force, COPD diagnosis and severity of COPD. These variables were all included in the regression models in which the 0.05 significance level was retained for final entry. According to the GOLD classification, severity of COPD was introduced as a dichotomous variable, differentiating severe and very severe COPD (FEV1 $<50 \%$ pred) from moderate and mild COPD. PIFs at different resistances were compared via one-way ANOVA. To compare PIFs at different resistances between COPD patients and elderly controls, a two-sided ANOVA analysis was carried out. A value of $\mathrm{p}<0.05$ was considered significant.

\section{RESULTS}

In total, 26 COPD patients and 14 controls were included the study. Table 1 demonstrates the baseline characteristics of both groups. In order to investigate which parameters may determine the PIF as assessed by the in-check dial, a correlation analysis was performed in the whole study population $(n=40)$ as well as in the COPD subgroup $(n=26$; fig. 1). In both groups, PIF measured by the in-check method at zero resistance (PIF device) correlated best with the PIF measured during spirometry (whole group: $r=0.51$; COPD: $\mathrm{r}=0.58 ; \mathrm{p}<0.005)$. In the total study group, the PIF device also significantly $(p<0.005)$ correlated with age $(r=-0.5)$, FVC $(\mathrm{r}=0.46)$, MIP $(\mathrm{r}=0.42)$, MEP $(\mathrm{r}=0.5)$, peak expiratory flow $(\mathrm{r}=0.46)$ and height $(\mathrm{r}=0.4$; data not shown $)$. No statistically

\begin{tabular}{|c|c|c|c|}
\hline \multirow[t]{2}{*}{ TABLE 1} & \multicolumn{3}{|c|}{$\begin{array}{l}\text { Baseline characteristics of chronic obstructive } \\
\text { pulmonary disease (COPD) patients and } \\
\text { matched elderly controls }\end{array}$} \\
\hline & Elderly COPD & Elderly controls & p-value \\
\hline Subjects $n$ & 26 & 14 & \\
\hline Age yrs & $76.0 \pm 4.5$ & $79.0 \pm 5.6$ & 0.07 \\
\hline BMI $\mathrm{kg} \cdot \mathrm{m}^{-2}$ & $25.6 \pm 4.0$ & $24.4 \pm 2.2$ & 0.3 \\
\hline Height cm & $167 \pm 0.77$ & $165 \pm 0.07$ & 0.36 \\
\hline FVC L & $2.23 \pm 0.76$ & $2.61 \pm 0.68$ & 0.13 \\
\hline FVC \% pred & $67.6 \pm 17$ & $92.6 \pm 11$ & $0.001^{\#}$ \\
\hline FEV $_{1} \mathrm{~L}$ & $1.23 \pm 0.59$ & $1.98 \pm 0.52$ & $0.003^{\#}$ \\
\hline FEV $1 \%$ pred & $48.9 \pm 20$ & $90.9 \pm 11$ & $0.001^{\#}$ \\
\hline PIF L· $\min ^{-1}$ & $169 \pm 66$ & $179 \pm 65$ & 0.68 \\
\hline PEF L· $\min ^{-1}$ & $199 \pm 99$ & $270 \pm 89$ & $0.03^{\#}$ \\
\hline MIP $\mathrm{cmH}_{2} \mathrm{O}$ & $41.1 \pm 22$ & $42.3 \pm 26$ & 0.87 \\
\hline MEP $\mathrm{cmH}_{2} \mathrm{O}$ & $77.8 \pm 37$ & $67.7 \pm 41$ & 0.43 \\
\hline \multicolumn{4}{|c|}{$\begin{array}{l}\text { Data are presented as mean } \pm \mathrm{SD} \text {, unless otherwise stated. BMI: body mass } \\
\text { index; FVC: forced vital capacity; \% pred: \% predicted; FEV1: forced expiratory } \\
\text { volume in one second; PIF: peak inspiratory flow; PEF: peak expiratory flow; } \\
\text { MIP: maximum inspiratory pressure; MEP: maximum expiratory pressure. } \\
\text { \#: statistically significant differences. }\end{array}$} \\
\hline
\end{tabular}



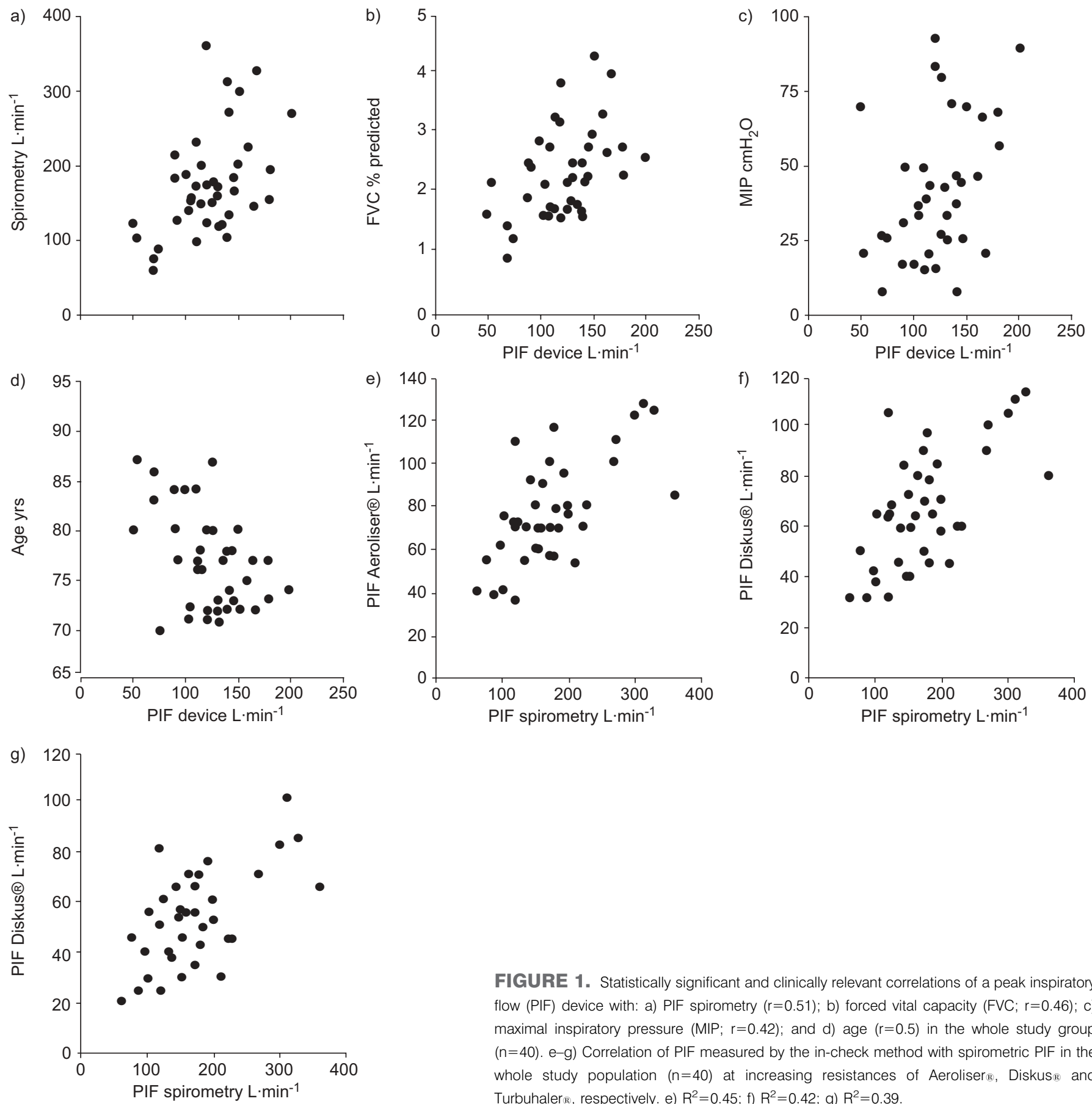

FIGURE 1. Statistically significant and clinically relevant correlations of a peak inspiratory flow (PIF) device with: a) PIF spirometry $(r=0.51)$; b) forced vital capacity ( $F V C ; r=0.46) ; c$ ) maximal inspiratory pressure (MIP; $r=0.42)$; and $d)$ age $(r=0.5)$ in the whole study group $(n=40)$. e-g) Correlation of PIF measured by the in-check method with spirometric PIF in the whole study population $(n=40)$ at increasing resistances of Aeroliser $\mathbb{B}$, Diskus $\mathbb{B}$ and Turbuhaler®, respectively. e) $R^{2}=0.45$; f) $R^{2}=0.42 ;$ g) $R^{2}=0.39$.

significant correlation could be found with body mass index, Tiffeneau index, FEV1, FEV1 \% pred and FVC \% pred. A stepwise multiple regression was performed on all 40 participants to study independent predictors of the PIF device. It was found that spirometric PIF (partial $R^{2}: 0.25, p=0.0008$ ) and age (partial $R^{2}: 0.12, p=0.014$ ) independently contributed to the variance of PIF device $\left(R^{2}: 0.37, p<0.001\right)$. The other variables could not be retained. Stepwise multiple regression for the PIF over the Aeroliser ${ }^{\circledR}$, Diskus ${ }^{\circledR}$ and Turbuhaler ${ }^{\circledR}$ could only withhold PIF measured by spirometry as an independent predictor (Aeroliser ${ }^{\circledR}$ : $\mathrm{R}^{2}=0.45, \quad \mathrm{p}<0.001$;
Diskus ${ }_{\mathbb{R}}: \mathrm{R}^{2}=0.42, \mathrm{p}<0.0001$; Turbuhaler ${ }_{\mathbb{}}: \mathrm{R}^{2}=0.39, \mathrm{p}<0.001$; fig 1).

The in-check device was pre-set at resistances that corresponded to the airflow resistances of the Aeroliser ${ }^{\circledR}$, Diskus ${ }_{\circledR}$ and Turbuhaler ${ }^{\circledR}$. As expected, in COPD patients as well as in the elderly control population, the PIF rates measured by the in-check method were significantly lower with increasing resistances (one-way ANOVA and Bonferonni multiple comparison test, $\mathrm{p}<0.01$; data not shown). When COPD patients were compared with elderly controls, no statistically significant 


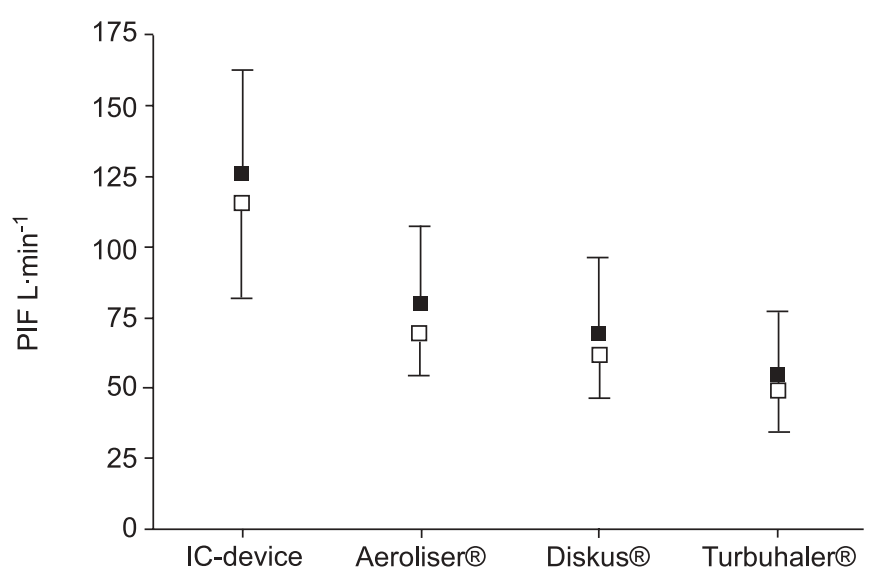

FIGURE 2. Mean \pm SD peak inspiratory flow (PIF) rates as assessed by the incheck (IC) device method in elderly chronic obstructive pulmonary disease (COPD) patients ( $\mathbf{\square} ; n=26)$ and healthy controls $(\square ; n=14)$. PIFs over the IC device were compared with PIFs over increasing additional resistances, which correspond to the resistance of the Aeroliser ${ }_{\circledast}$, Diskus ${ }^{\circledR}$ and Turbuhaler ${ }^{*}$. In controls and COPD patients the resistance of the device determines PIF across the device $(p=0.01)$ but presence or absence of COPD is not related $(p>0.05)$.

difference could be observed (two-way ANOVA, $p=0.09$ ) in the PIFs between both groups at any given resistance (fig. 2).

PIFs measured by the in-check method were subsequently divided into four different categories: flows $>60 \mathrm{~L} \cdot \mathrm{min}^{-1}$; flows 45-60 L. $\mathrm{min}^{-1}$; flows $30-45 \mathrm{~L} \cdot \mathrm{min}^{-1}$; and flows $<30 \mathrm{~L} \cdot \mathrm{min}^{-1}$. An arbitrary cut-off point was selected at $45 \mathrm{~L} \cdot \mathrm{min}^{-1}$ in order to distinguish therapeutic flows from subtherapeutic levels. Therapeutic flows $>45 \mathrm{~L} \cdot \mathrm{min}^{-1}$ were obtained in $87.5 \%$ $(n=35), 80 \% \quad(n=32)$ and $70 \% \quad(n=28)$ of cases for the Aeroliser $_{\AA}$, Diskus ${ }_{\circledR}$ and Turbuhaler , respectively. When comparing the flow rates to the previously described minimal flow rate of $30 \mathrm{~L} \cdot \mathrm{min}^{-1}, 12.5 \%(n=5)$ of the Turbuhaler ${ }^{\circledR}$ users were unable to generate the minimal required flow, whereas all patients $(n=40)$ could attain this minimal flow when using the Aeroliser ${ }_{\circledR}$ or Diskus ${ }^{\circledR}$. A statistically significant difference between COPD patients and elderly controls could not be observed on any of the different categories (Fisher-exact test, $\mathrm{p}>0.05$; fig. 3).

\section{DISCUSSION}

The present study examines the PIF that can be generated over different DPIs in an elderly patient population by using the incheck method. It was demonstrated that the PIF over a DPI positively correlated with the spirometric PIF, FVC and MIP, while a negative, but significant, correlation could be observed with age. Stepwise multiple regression analysis could only retain spirometric PIF as an independent predictor for explaining the variance of PIF across the device at any given resistance. The presence and severity of COPD did not contribute to the present model. When the elderly COPD patients and matched healthy controls were compared, no difference was observed in the subjects' ability to achieve acceptable flows over the different DPIs tested. Nevertheless, an important number of patients were unable to reach the PIF recommended for an optimal therapeutic effect.

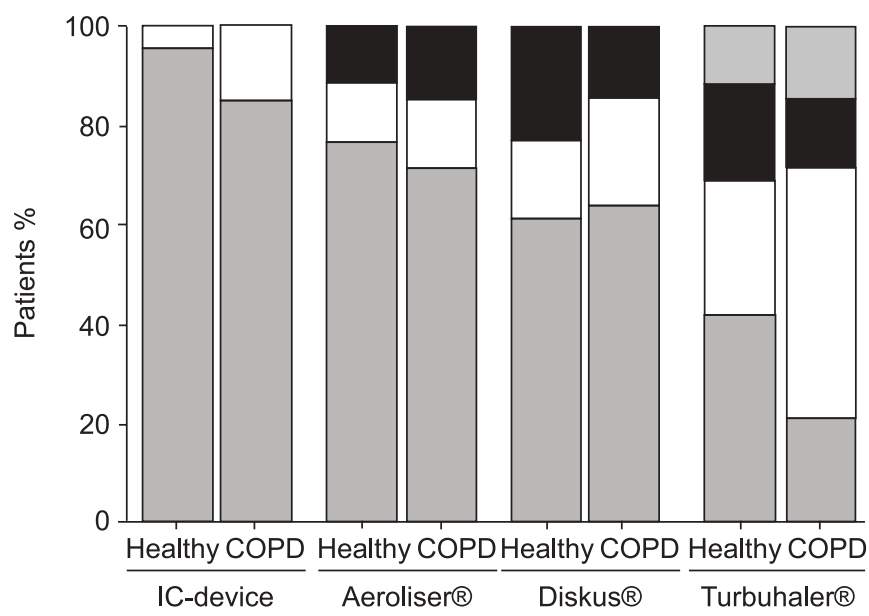

FIGURE 3. A bar chart comparing the percentages of patients who achieved peak inspiratory flows within a certain flow range at different resistances as simulated by the in-check (IC) device method. Chronic obstructive pulmonary patients (COPD) patients $(n=26)$ were compared with matched healthy controls $(\mathrm{n}=14) . \square:<30 \mathrm{~L} \cdot \mathrm{min}^{-1} ; \mathbf{\square}: 30-45 \mathrm{~L} \cdot \mathrm{min}^{-1} ; \square: 45-60 \mathrm{~L} \cdot \mathrm{min}^{-1} ; \square:>60 \mathrm{~L} \cdot \mathrm{min}^{-1}$.

The PIF over a DPI depends on the MIP a patient can generate, but also on the resistance attributable to the device and to the patients' airways [8]. The current data are consistent with previous reports in asthmatics and COPD patients $[5,33,34]$. In these publications, it was demonstrated that lung function variables predictive for PIF across a DPI were MIP, spirometric PIF and inspiratory capacity, whereas FEV1, as an expression of the severity of illness, did not correlate with the MIF rate over a device. Similar correlations were found in the present study in addition to a negative correlation between PIF device and age, which could be expected given the age dependency of PIF in prediction equations. Therefore, it is very likely that in an elderly population the optimal use of DPIs decreases with age for reasons of reduced inspiratory muscle force, lower spirometric PIF [17] and the fact that with age the correct use of a DPI becomes more difficult $[15,16]$.

The present data could not demonstrate a significant difference between the elderly COPD population and the healthy control group when looking at inspiratory flows across the different devices. As COPD is, above all, an expiratory disease that does not directly affect inspiratory flow rates, this finding is not surprising and has already been previously reported $[5,34]$. In a younger COPD population (mean age 56 yrs) it has been demonstrated that all patients were able to generate PIFs $>50 \mathrm{~L} \cdot \mathrm{min}^{-1}$ against several resistances [34]. The authors consequently concluded that each COPD patient could benefit from all the different types of DPIs available. In the elderly study population, however, flow rates $<45 \mathrm{~L} \cdot \mathrm{min}^{-1}$ were present in $12.5 \%(n=5), 20 \%(n=8)$ and in $30 \%(n=12)$ of cases for the Aeroliser ${ }_{\circledast}$, Diskus ${ }_{\circledR}$ and Turbuhaler ${ }_{\circledast}$, respectively. This is consistent with the findings of Nsour et al. [16], who described in $23(31 \%)$ out of 74 COPD patients (mean age 79 yrs) PIFs $<40 \mathrm{~L} \cdot \mathrm{min}^{-1}$ when using the Turbuhaler ${ }^{\circledR}$. The fact that DEWAR et al. [32] found subtherapeutic flows $<40 \mathrm{~L} \cdot \mathrm{min}^{-1}$ over the Turbohaler ${ }^{\circledR}$ in only $17(17 \%)$ out of 100 COPD patients might be explained by the lower mean age (69 yrs) of 
their population. As in the current study, 15 younger patients (mean age $36 \mathrm{yrs}$ ) were all able to achieve PIFs $>60 \mathrm{~L} \cdot \mathrm{min}^{-1}$ when using the same device and protocol (data not shown). The present authors believe that age, much more than COPD severity, should be taken into account when prescribing DPIs for stable COPD in an elderly population.

Most authors agree on the fact that in the case of reduced inspiratory flow, a low-resistance DPI that is relatively insensitive to changes in airflow will be more beneficial. Manufacturers should, therefore, be encouraged to label products with its specific resistance and the dose emitted at different flow rates [14]. The present data demonstrate that $30 \%$ of the elderly population were not able to reach the arbitrary cut-off flow of $45 \mathrm{~L} \cdot \mathrm{min}^{-1}$ when using a Turbuhaler ${ }^{\circledR}$, while only 20 and $12.5 \%$ of the population had similar problems with the Diskus ${ }^{\circledR}$ and Aeroliser ${ }^{\circledR}$, respectively. Turbuhaler ${ }^{\circledR}$ and Aeroliser ${ }^{\circledR}$ are less effective at a PIF $<60 \mathrm{~L} \cdot \mathrm{min}^{-1}$, whereas the Diskus ${ }^{\circledR}$ seems to have an equal effect at a PIF $30-60 \mathrm{~L} \cdot \mathrm{min}^{-1}[6$, 22-30]. This could mean that, in contrast to the Diskus ${ }^{\circledR}$, the number of patients with subtherapeutic flows over the Aeroliser ${ }^{\circledR}$ or Turbuhaler ${ }^{\circledR}$ is even underestimated. Whether this suboptimal flow also results in a different clinical outcome in terms of symptom relief, reduction of exacerbations and lower mortality is currently not known. This should be investigated further in future studies.

In conclusion, the present study demonstrates that in elderly patients the ability to generate sufficient inspiratory flow across a dry powder inhaler is compromised, irrespective of the presence of chronic obstructive pulmonary disease. This is an important finding as elderly people are generally encouraged to use a dry powder inhaler instead of metered dose inhalers, due to its easier application. Ideally, the choice for the most appropriate dry powder inhaler in elderly patients should, therefore, depend on the objective measurement of peak inspiratory flow against a certain resistance. Alternatively, the direct choice of a lowresistance dry powder inhaler, which is relative insensitive to changes in peak inspiratory flow at lower flow levels, might be beneficial in situations such as exacerbations characterised by a further reduction of inspiratory flow [12, 21, 35].

\section{REFERENCES}

1 Jones V, Fernandez C, Diggory P. A comparison of large volume spacer, breath-activated and dry powder inhalers in older people. Age Ageing 1999; 28: 481-484.

2 Roche N, Chinet T, Huchon G. Ambulatory inhalation therapy in obstructive lung diseases. Respiration 1997; 64: 121-130.

3 Sumby B, Slater A, Atkins PJ, Prime D. Review of dry powder inhalers. Adv Drug Deliv Rev 1997; 26: 51-58.

4 Broeders ME, Molema J, Vermue NA, Folgering HT. Peak inspiratory flow rate and slope of the inhalation profiles in dry powder inhalers. Eur Respir J 2001; 18: 780-783.

5 Broeders ME, Molema J, Hop WC, Folgering HT. Inhalation profiles in asthmatics and COPD patients: reproducibility and effect of instruction. J Aerosol Med 2003; 16: 131-141.

6 Broeders ME, Molema J, Vermue NA, Folgering HT. In Check Dial: accuracy for Diskus and Turbuhaler. Int J Pharm 2003; 252: 275-280.
7 Bronsky EA, Grossman J, Henis MJ, et al. Inspiratory flow rates and volumes with the Aerolizer dry powder inhaler in asthmatic children and adults. Curr Med Res Opin 2004; 20: 131-137.

8 Clark AR, Hollingworth AM. The relationship between powder inhaler resistance and peak inspiratory conditions in healthy volunteers-implications for in vitro testing. J Aerosol Med 1993; 6: 99-110.

9 Amirav I, Newhouse MT, Mansour Y. Measurement of peak inspiratory flow with in-check dial device to simulate low-resistance (Diskus) and high-resistance (Turbohaler) dry powder inhalers in children with asthma. Pediatr Pulmonol 2005; 39: 447-451.

10 Adachi YS, Adachi Y, Itazawa T, Yamamoto J, Murakami G, Miyawaki T. Ability of preschool children to use dry powder inhalers as evaluated by In-Check Meter. Pediatr Int 2006; 48: 62-65.

11 Broeders ME, Molema J, Hop WC, Vermue NA, Folgering HT. The course of inhalation profiles during an exacerbation of obstructive lung disease. Respir Med 2004; 98: 1173-1179.

12 Richter K. Successful use of DPI systems in asthmatic patients-key parameters. Respir Med 2004; 98: Suppl. B, S22-S27.

13 Engel T, Heinig JH, Madsen F, Nikander K. Peak inspiratory flow and inspiratory vital capacity of patients with asthma measured with and without a new dry-powder inhaler device (Turbuhaler). Eur Respir J 1990; 3: 1037-1041.

14 Chrystyn $H$. Is inhalation rate important for a dry powder inhaler? Using the In-Check Dial to identify these rates. Respir Med 2003; 97: 181-187.

15 Diggory P, Fernandez C, Humphrey A, Jones V, Murphy M. Comparison of elderly people's technique in using two dry powder inhalers to deliver zanamivir: randomised controlled trial. BMJ 2001; 322: 577-579.

16 Nsour WM, Alldred A, Corrado J, Chrystyn H. Measurement of peak inhalation rates with an in-check meter to identify an elderly patient's ability to use a turbuhaler. Respir Med 2001; 95: 965-968.

17 Janssens JP, Pache JC, Nicod LP. Physiological changes in respiratory function associated with ageing. Eur Respir J 1999; 13: 197-205.

18 Jarvis S, Ind PW, Shiner RJ. Inhaled therapy in elderly COPD patients; time for re-evaluation? Age Ageing 2007; 36: 213-218.

19 Quanjer PH, Tammeling GJ, Cotes JE, Pedersen OF, Peslin R, Yernault JC. Lung volumes and forced ventilatory flows. Report Working Party Standardization of Lung Function Tests, European Community for Steel and Coal. Official Statement of the European Respiratory Society. Eur Respir J Suppl 1993; 16: 5-40.

20 Black LF, Hyatt RE. Maximal respiratory pressures: normal values and relationship to age and sex. Am Rev Respir Dis 1969; 99: 696-702.

21 van der Palen J. Peak inspiratory flow through diskus and turbuhaler, measured by means of a peak inspiratory flow meter (In-Check DIAL). Respir Med 2003; 97: 285-289.

22 Meakin BJ, Ganderton D, Panza I, Ventura P. The effect of flow rate on drug delivery from the Pulvinal, a highresistance dry powder inhaler. J Aerosol Med 1998; 11: 143-152. 
23 Prime D, Grant AC, Slater AL, Woodhouse RN. A critical comparison of the dose delivery characteristics of four alternative inhalation devices delivering salbutamol: pressurized metered dose inhaler, Diskus inhaler, Diskhaler inhaler, and Turbuhaler inhaler. J Aerosol Med 1999; 12: 75-84.

24 Bisgaard H, Klug B, Sumby BS, Burnell PK. Fine particle mass from the Diskus inhaler and Turbuhaler inhaler in children with asthma. Eur Respir J 1998; 11: 1111-1115.

25 Chew NY, Chan HK. In vitro aerosol performance and dose uniformity between the Foradile Aerolizer and the Oxis Turbuhaler. J Aerosol Med 2001; 14: 495-501.

26 Borgström L. Deposition patterns with Turbuhaler. J Aerosol Med 1994; 7: Suppl. 1, S49-S53.

27 Borgstrom L, Bondesson E, Moren F, Trofast E, Newman SP. Lung deposition of budesonide inhaled via Turbuhaler: a comparison with terbutaline sulphate in normal subjects. Eur Respir J 1994; 7: 69-73.

28 Nielsen KG, Auk IL, Bojsen K, Ifversen M, Klug B, Bisgaard H. Clinical effect of Diskus dry-powder inhaler at low and high inspiratory flow-rates in asthmatic children. Eur Respir J 1998; 11: 350-354.

29 Tarsin WY, Pearson SB, Assi KH, Chrystyn H. Emitted dose estimates from Seretide Diskus and Symbicort
Turbuhaler following inhalation by severe asthmatics. Int J Pharm 2006; 316: 131-137.

30 Nielsen KG, Skov M, Klug B, Ifversen M, Bisgaard $H$. Flow-dependent effect of formoterol dry-powder inhaled from the Aerolizer. Eur Respir J 1997; 10: 2105-2109.

31 Derom E, Borgstrom L, Van Schoor J, Lofroos AB, Pauwels R. Lung deposition and protective effect of terbutaline delivered from pressurized metered-dose inhalers and the Turbuhaler in asthmatic individuals. Am J Respir Crit Care Med 2001; 164: 1398-1402.

32 Dewar MH, Jamieson A, McLean A, Crompton GK. Peak inspiratory flow through Turbuhaler in chronic obstructive airways disease. Respir Med 1999; 93: 342-344.

33 Parry-Billings M, Birrell C, Oldham L, O'Callaghan C. Inspiratory flow rate through a dry powder inhaler (Clickhaler) in children with asthma. Pediatr Pulmonol 2003; 35: 220-226.

34 Sarinas PS, Robinson TE, Clark AR, Canfield J Jr, Chitkara RK, Fick RB Jr. Inspiratory flow rate and dynamic lung function in cystic fibrosis and chronic obstructive lung diseases. Chest 1998; 114: 988-992.

35 Cegla UH. Pressure and inspiratory flow characteristics of dry powder inhalers. Respir Med 2004; 98: Suppl. A, S22-S28. 